Science transcended

\title{
George M. Marsden
}

The Origins of Life: Evolution as Creation.

By Hoimar v. Ditfurth. Translated by Peter Heinegg.

Harper \& Row: 1983. Pp.280. £9.50, \$14.95.

FOR well over a century a popular belief has been that religion and science stand at opposite ends in the cultural evolution of human intelligence. Gradually but irreversibly, according to this view, primitive religious superstitions are replaced by empirically based scientific conclusions. Although most scholars have abandoned the positivistic aspects, the concept of an essential conflict between science and religion has been so indelibly imprinted on the collective intelligence of modern people that it will be difficult to displace.

Hoimar v. Ditfurth, well known in Germany as an author of popular scientific books, attempts to destroy this mythology with the weapons of science itself. In sometimes brilliant and fascinating discussion, Ditfurth argues that today's science is highly conducive to religious belief and provides strong presumptions for faith in a "beyond" or a transcendent creative intelligence.

At his most effective, Ditfurth meets objections to the belief in a transcendent mind that guides the universe. Evolutionary theory of the development of mind together with our knowledge that the universe could well include billions of intelligent life forms, suggests that our own understanding of reality is far from definitive. The mysteries on the edges of our scientific inquiry suggest that there are other dimensions to which our consciousness does not yet have direct access.

This concept can be supported by an evolutionary epistemology in which the categories for thought that Kant believed were a priori postulates, are considered to have developed $a$ posteriori in the collective consciousness of the species. Ditfurth uses the analogy of chickens which have imprinted in their pristine intelligence fears of their mortal enemies. So, he argues, we humans have evolved inborn mental structures that compel us to perceive reality through categories such as spatiality, temporality or causality. Our conclusions based on this "inborn" intelligence seem so compelling because they have been well attuned to ordinary circumstances. Nonetheless, twentieth-century science and philosophy of science both show how arbitrary and hypothetical is even the most sophisticated of this empirical intelligence. We have a presumption, then, for supposing there are dimensions of reality to which our minds are not fully attuned.

There is another presumption, based on the mystery of a universe structured to produce life. How is it, Ditfurth asks, that when the universe emerged from the big bang it contained the capability of producing new forms, including life forms? This astounding capability, he argues, makes sense best if we view ongoing evolution as part of creation. That a transcendent mind is guiding the natural processes he finds confirmed by the fact that evolution creates more and more intelligence and consciousness. The cosmos is thus moving in the direction of blending with the principle of mind.

So Ditfurth has produced a natural theology, a rare enterprise in this century. His outlook is deistic in positing a creator as necessary to account for the incredible design of nature, but not deistic in that the transcendent maintains an immanent relationship with the universe. Moreover, in contrast to the deist's difficulties in explaining why God, "the perfect watchmaker", should have permitted imperfections, Ditfurth suggests a way of resolving the problem of evil. The imperfections of creation are necessary to the evolutionary creative process. While chance developments may bring much pain of constant readjustments, they also provide the freedom that keeps the processes going. An evolutionary outlook, Ditfurth emphasizes, balances chance and lawfulness. Pure chance would lead to meaningless chaos. Total governance by fixed laws would lead to equally meaningless automatism and stagnation. In combination, however, the laws of nature govern the course of chance.

Evolutionary theory provides one other presumption favouring religious belief. The collective intelligence accumulated by species is typically far superior to that based on the experience of any of its individual members. The same may apply to aspects of human intelligence. Some social theorists, for instance, have suggested the politically comforting theory that cultural systems may survive because they embody a supra-intelligence superior to that of any of the individuals who govern. So it may be dangerous to overthrow long-established cultural practices and taboos just because we can not understand the reasons for them. Similarly, we might presume that some long-standing religious beliefs may be based on insight superior to those grounded on mere empirical judgement. So Ditfurth neatly reverses the usual evolutionary assumptions about science and religion. Rather than being a vestige of primitivism, religious beliefs may embody superior insights not yet fully available to our conscious intelligence.

Unfortunately, although Ditfurth has some highly suggestive insights on religion based on evolutionary theory, he considerably overestimates their originality. The first section of his book is written with a particularly arrogant tone, as though he were the first person in the twentieth century to realize that science and religion can readily be harmonized. He ignores the many modern theologians who have viewed scientific and religious beliefs as complementary, not contradictory.

Moreover, despite some genuine originality, Ditfurth overestimates the novelty of his efforts to integrate specific evolutionary insights and theology. For the past century a host of theologians and philosophers have been proposing variations on this theme. Ditfurth clearly has an advantage of a firm command of scientific literature. But he tends to present his work as absolute insights concerning the evolutionary processes. In the last analysis, God for him is evolution.

So, despite his claims that readers will not be "asked to doubt even a fraction of their religious faith", Ditfurth dismisses out of hand all traditional theologies in favour of his evolutionary formulations. Traditional theologies, he assumes, are hopelessly outdated and their perpetuation is the cause of the decline of the churches. Only a core belief in a transcendent creator, he argues, is a superior primal insight that is consistent with current scientific thought.

But does not this confidence in interpreting current evolutionary theory conflict with Ditfurth's own warnings not to overestimate the present state of human intelligence? Certainly, as far as Christianity is concerned, the decline of churches today is not obviously attributable to the promotion of outmoded theologies. Rather, the churches that have declined most dramatically are typically those that have made the greatest efforts to keep their theologies up-to-date. Meanwhile the churches that grow are usually those with more-or-less traditional theologies. Of course, popularity is no evidence of correctness of belief. But Ditfurth's insights might support more traditional beliefs than he is ready to acknowledge. Evolution after all is largely a conservative process, preserving accumulated achievements while adjusting them to current challenges. So might not a more consistent evolutionary approach to religion be to conserve the vast majority of past developments while adjusting them to new conditions and insights? Evolutionary theory by itself can not finally adjudicate on such issues.

George M. Marsden is Professor of History at Calvin College, Grand Rapids, Michigan. He is author of Fundamentalism and American Culture, published by Oxford University Press in 1981 . 